\title{
Inflatable Re-entry Vehicle Experiment (IRVE) Design Overview
}

\author{
Stephen J. Hughes ${ }^{*}$, Robert A. Dillman ${ }^{\dagger}$, Brett R. Starr ${ }^{\ddagger}$, Ryan A. Stephan ${ }^{\S}$, Michael C. Lindell ${ }^{* *}$, Charles J. Player ${ }^{\dagger \dagger}$, \\ and Dr. F. McNeil Cheatwood \\ NASA Langley Research Center, Hampton, VA, 23681
}

\begin{abstract}
Inflatable aeroshells offer several advantages over traditional rigid aeroshells for atmospheric entry. Inflatables offer increased payload volume fraction of the launch vehicle shroud and the possibility to deliver more payload mass to the surface for equivalent trajectory constraints. An inflatable's diameter is not constrained by the launch vehicle shroud. The resultant larger drag area can provide deceleration equivalent to a rigid system at higher atmospheric altitudes, thus offering access to higher landing sites. When stowed for launch and cruise, inflatable aeroshells allow access to the payload after the vehicle is integrated for launch and offer direct access to vehicle structure for structural attachment with the launch vehicle. They also offer an opportunity to eliminate system duplication between the cruise stage and entry vehicle. There are however several potential technical challenges for inflatable aeroshells. First and foremost is the fact that they are flexible structures. That flexibility could lead to unpredictable drag performance or an aerostructural dynamic instability. In addition, durability of large inflatable structures may limit their application. They are susceptible to puncture, a potentially catastrophic insult, from many possible sources. Finally, aerothermal heating during planetary entry poses a significant challenge to a thin membrane. NASA Langley Research Center and NASA's Wallop's Flight Facility are jointly developing inflatable aeroshell technology for use on future NASA missions. The technology will be demonstrated in the Inflatable Re-entry Vehicle Experiment (IRVE). This paper will detail the development of the initial IRVE inflatable system to be launched on a Terrier/Orion sounding rocket in the fourth quarter of CY2005. The experiment will demonstrate achievable packaging efficiency of the inflatable aeroshell for launch, inflation, leak performance of the inflatable system throughout the flight regime, structural integrity when exposed to a relevant dynamic pressure and aerodynamic stability of the inflatable system. Structural integrity and structural response of the inflatable will be verified with photogrammetric measurements of the back side of the aeroshell in flight. Aerodynamic stability as well as drag performance will be verified with on board inertial measurements and radar tracking from multiple ground radar stations. The experiment will yield valuable information about zero-g vacuum deployment dynamics of the flexible inflatable structure with both inertial and photographic measurements. In addition to demonstrating inflatable technology, IRVE will validate structural, aerothermal, and trajectory modeling techniques for the inflatable. Structural response determined from photogrammetrics will validate structural models, skin temperature measurements and additional in-depth temperature measurements will validate material thermal performance models, and on board inertial measurements along with radar tracking from multiple ground radar stations will validate trajectory simulation models.
\end{abstract}

\footnotetext{
* IRVE Lead Design Engineer, Mechanical Systems Branch, NASA LaRC/MS432, AIAA Member

${ }^{\dagger}$ IRVE Mechanical Engineer, Exploration Systems Engineering Branch, NASA LaRC/MS489,AIAA Member

* IRVE Flight Mechanics Lead, Systems Engineering Branch, NASA LaRC/MS489, AIAA Member

§ IRVE Thermal Analyst, Structural and Thermal Systems Branch, NASA LaRC/MS431, AIAA Member

${ }^{* *}$ IRVE Structural Analyst, and Thermal Systems Branch, NASA LaRC/MS431, AIAA Member

${ }^{\dagger}$ IRVE Project Manager, Exploration Systems Engineering Branch, NASA LaRC/MS489, Non-Member

\# IRVE Principle Investigator,ESSOTD, NASA LaRC/MS176, Senior Member AIAA
} 


\section{Nomenclature}

$\begin{array}{ll}\text { ARF } & =\text { Aeroballistic Research Facility } \\ A O A & =\text { Angle of attack } \\ D o F & =\text { Degree of Freedom } \\ D V T & =\text { Design Validation Test } \\ \text { LaRC } & =\text { Langley Research Center } \\ \text { LAURA } & =\text { Langley Aerothermodynamic Upwind Relaxation Algorithm } \\ M & =\text { Mach Number } \\ M L I & =\text { Multi-Layer Insulation } \\ M S L & =\text { Mars Science Laboratory } \\ N S R O C & =\text { NASA Sounding Rocket Operations Contract } \\ P O S T & =\text { Program to Optimize Simulated Trajectories } \\ P V U & =\text { Pattern Validation Unit } \\ R F & =\text { Radio Frequency } \\ R T G & =\text { Radioisotope Thermoelectric Generator } \\ S R P H & =\text { Sounding Rocket Program Handbook } \\ T / M & =\text { Telemetry Module } \\ T P S & =\text { Thermal Protection System } \\ W F F & =\text { Wallops Flight Facility }\end{array}$

\section{Introduction}

$\mathrm{R}$ IGID Aeroshell systems are rapidly approaching the payload limit that the technology can deliver while fitting within the payload envelope existing launch vehicles. NASA's new exploration directive may require significantly heavier logistics payloads to be pre-positioned on Mars prior to the crew's arrival. Inflatable deployable aeroshells offer an alternative to the on-orbit assembly of rigid aeroshells large enough to decelerate heavy logistics payloads on arrival at Mars. Initial studies of inflatable aeroshell delivery systems indicate that the inflatable system will also require a smaller payload mass fraction than traditional rigid aeroshell systems. ${ }^{1}$ In fact, the payload mass fraction of an inflatable aeroshell system is better than that calculated in Ref. 1, because that study erroneously added $389 \mathrm{~kg}$ of backshell mass to the system when a inflatable system as described in that study would have required no backshell at all. Inflatable aeroshells also require a smaller payload volume fraction than traditional rigid aeroshells, and the packaging flexibility of the inflatable allows for more efficient use of available payload volume in existing launch shrouds.

Rigid aeroshell systems designed to fit within the payload envelope of currently available launch vehicles typically require the use of a backshell to protect the payload from aft side heating. The backshell is significant not only because the backshell adds mass to the TPS system taking away launch mass from the useable payload (as was mentioned earlier), but also because a backshell configuration effectively cocoons the payload (an undesirable arrangement for several reasons). Any structural attachments or electrical connections through the cocoon are potential leak paths for the heat of re-entry to reach the payload. These penetrations of the heatshield require extensive analysis and testing to validate their design. ${ }^{2}$ Removable doors are usually required to allow access to the payload after integration of the aeroshell. It is desirable to integrate energetic hardware such as Radioisotope Thermoelectric Generators (RTG's) at the last possible moment, even as late as when the payload and spacecraft are stacked on the launch vehicle. RTG's were once proposed for the large "nuclear option" long-duration rovers for rover for Mars Science Laboratory (MSL). Integration this late in the process requires a door in the aeroshell large enough to accommodate RTG installation. Such a large opening in the aeroshell presents a significant design challenge and requires considerable testing and development which costs the program both funding and schedule.

The rigid aeroshell is a highly effective insulator designed to keep the intense heat of entry from reaching the payload. This insulating capability is a double-edged sword, however, as it may interfere with thermal control of high-power payloads during interplanetary cruise. Trapping some heat may not be a significant problem, but again if RTGs are considered for use on the payload the waste heat generated must be transported through the aeroshell and rejected by an external radiator. This requires another series of potentially problematic penetration in the aeroshell.

Flexibility of packaging realized when employing an inflatable aeroshell relieves many of the difficulties inherent in the rigid system. Because of the low ballistic coefficient attainable with the inflatable aeroshell the heat of entry is reduced significantly for the same payload mass. An example of the difference in heating rate for an inflatable concept versus a rigid concept is shown in Fig. 1. This inflatable aeroshell system will likely not require a backshell because peak aft heating, typically around 3 percent of peak stagnation heating ${ }^{4}$, is only $0.2 \mathrm{~W} / \mathrm{cm}^{2}$. 


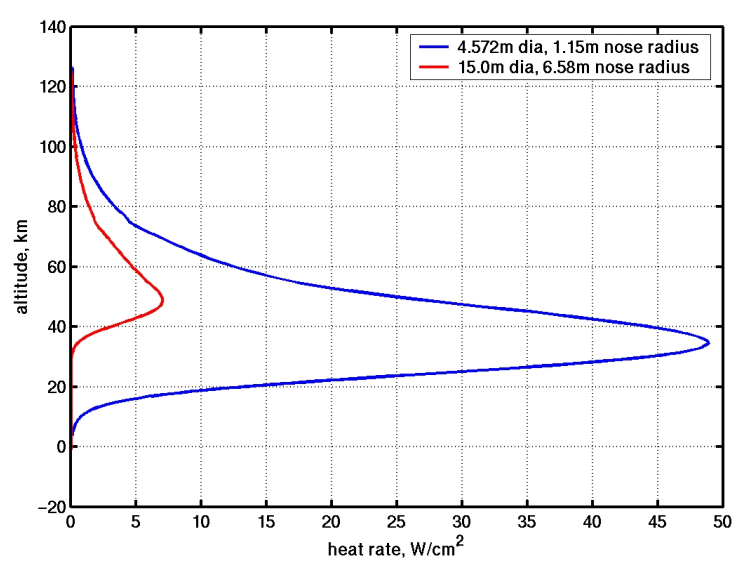

Figure 1. Stagnation point convective heat rate vs. altitude for both a rigid and an inflatable MSL concept $6 \mathrm{~km} / \mathrm{s}$ entry with equivalent landed mass.
Heating rates this low would not require a thermal protection layer other than typical multi-layer insulation (MLI) blanketing. The elimination of a backshell allows access to the payload during all phases of integration, and allows direct structural and electrical connections between the payload, the spacecraft, and the launch vehicle. Without a backshell, payload systems can also be used for interplanetary cruise wherever prudent, thus eliminating component duplication. Again RTG-powered rovers are an excellent example. While cocooned in a rigid aeroshell it would be difficult to use the RTG for power generation due to the large amount of waste heat. As a result the cruise stage is required to carry solar panels to generate power during interplanetary transfer. With no backshell the RTG's could be configured to generate power for all phases of the mission eliminating unnecessary system mass. Other systems like thrusters, star trackers, antennae and radiators might also be able to be shared for all phases of the mission, further reducing system mass. Reducing overall system mass allows more launch mass to be allocated to the payload delivered to the surface.

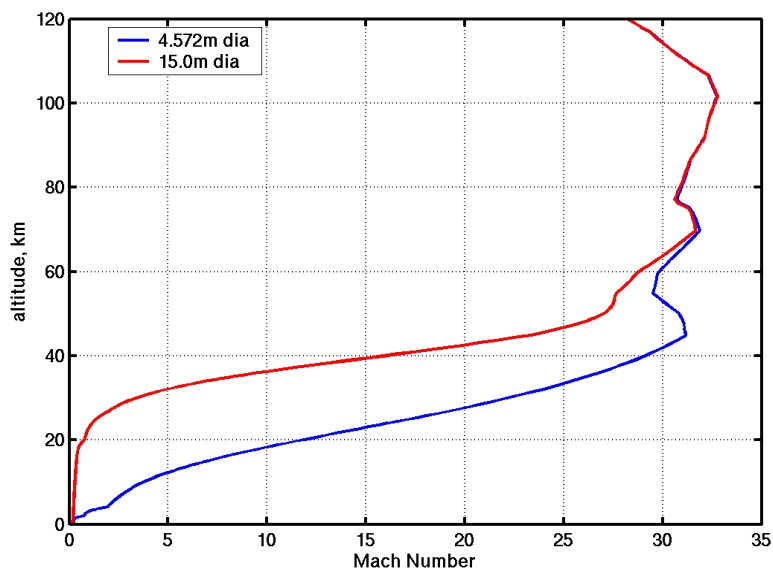

Figure 2. Mach number vs. altitude for both a rigid and an inflatable MSL concept with equivalent landed mass.
Another benefit comes from the inflatable system's ability to produce ballistic coefficients significantly lower than those achievable with a rigid system. Lower ballistic numbers allow the payload to decelerate higher in the atmosphere, which enables landing payloads at higher altitudes. Studies of Martian topology show that many of the most geologically interesting landing sites (the southern highlands) are at elevations $2 \mathrm{~km}$ above Mars mean radius and greater. ${ }^{5}$ Landing at many of these sites will be difficult (if not impossible) with current rigid aeroshell systems, because the rigid systems have difficulty achieving the parachute deployment conditions required by the entry descent and landing system for a successful landing. Figure 2 shows a comparison of entry Mach number profiles for MSL rigid and inflatable aeroshell concepts with the same entry conditions and landed mass. The plot shows the inflatable concept reaches parachute deployment velocity $(\mathrm{M}=2.0)$ more than $20 \mathrm{~km}$ higher in the atmosphere than the rigid aeroshell system.

\section{Background of the IRVE System}

An opportunity arose in 2004 for Langley Research Center (LaRC) to partner with Wallops Flight Facility (WFF) for a demonstration test of an inflatable aeroshell system on a Terrier/Orion sounding rocket. The test, the Inflatable Reentry Vehicle Experiment (IRVE) will be a first step in the incremental development of an inflatable aeroshell system. Given the Terrier/Orion performance, payload volume, and payload geometry available, it is not possible to match interplanetary entry conditions or entry vehicle size with the IRVE launch. Figure 3 shows a generic performance plot from the Sounding Rocket Program Handbook (SRPH) ${ }^{6}$ for the Terrier/Orion illustrating rocket performance for a range of payload weights. The payload volume available inside the "large" 17.25 inch Terrier/Orion launch shroud is 15.25 inches in diameter and roughly 80 inches in length. However, even without the ability to match planetary entry conditions, IRVE will provide a wealth of data for inflatable aeroshell development. Flexible materials that can survive planetary entry environments and methods for constructing an inflatable aeroshell from those materials will be demonstrated. IRVE will also illustrate the packaging efficiencies achievable with an 


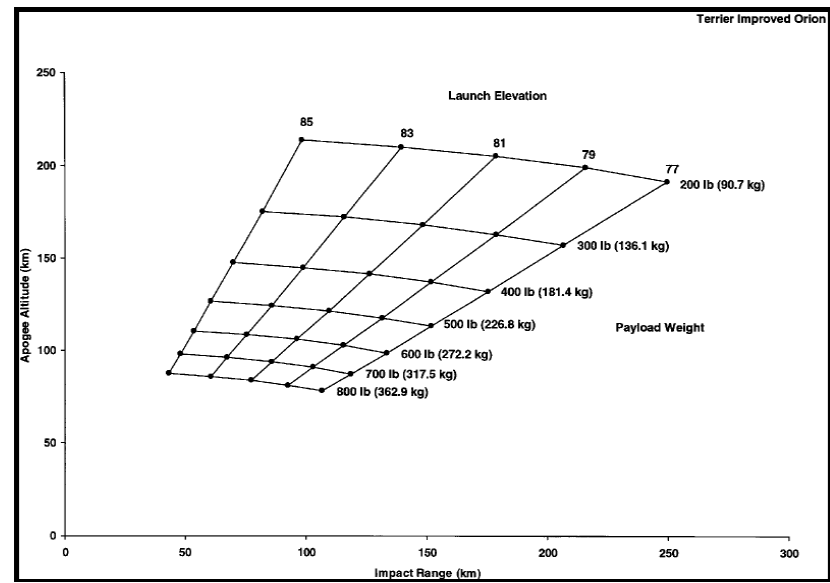

Figure 3. Terrier-Improved Orion launch vehicle predicted performance. inflatable aeroshell constructed of suitable flight materials. Leak performance of the inflatable structures will be determined for all phases of an entry. Exo-atmospheric deployment dynamics of the flexible inflatable structure will be measured, and used to validate the deployment dynamics modeling techniques. The structural integrity of the flexible inflatable will be demonstrated at a relevant dynamic pressure and questions about potential aero-structural interactions in free flight conditions that cannot be duplicated in ground test facilities will be answered. Aerodynamic stability (both static and dynamic) of a flexible inflatable blunt body will be demonstrated and flight test data will be used to verify computer modeling and ground testing techniques. Temperature measurements both on the surface and in-depth will be used to validate aerothermal heating modeling of the flexible body

and thermal performance of the flexible thermal protection layer. Finally, radar tracking data from multiple ground stations and on-board inertial measurement systems will validate trajectory simulation modeling that has incorporated all of the flexible body dynamics and aerodynamics generated with the above mentioned modeling techniques.

The performance of the Terrier/Orion launch vehicle limited the IRVE mass to approximately $100 \mathrm{~kg}$. For a $100 \mathrm{~kg}$ payload the Terrier/Orion provides enough exo-atmospheric flight time (roughly 250s) for the vehicle to separate from the launch vehicle and deploy the aeroshell before reentry. A maximum diameter of three meters was chosen for the aeroshell as a compromise between demonstrating a relevant aeroshell size and producing atmospheric entry conditions that would challenge the inflatable structure. Follow-on flights that will subject the inflatable to more challenging entry conditions (higher dynamic pressures, higher heating environments, larger scale, lifting trajectories) are in the planning stages. ${ }^{7}$

An engineering tool was created to calculate the surface area of the components of the inflatable aeroshell of the initial IRVE system concept (shown in cross-section in Fig. 4). Appropriate fabrics and films were selected for each

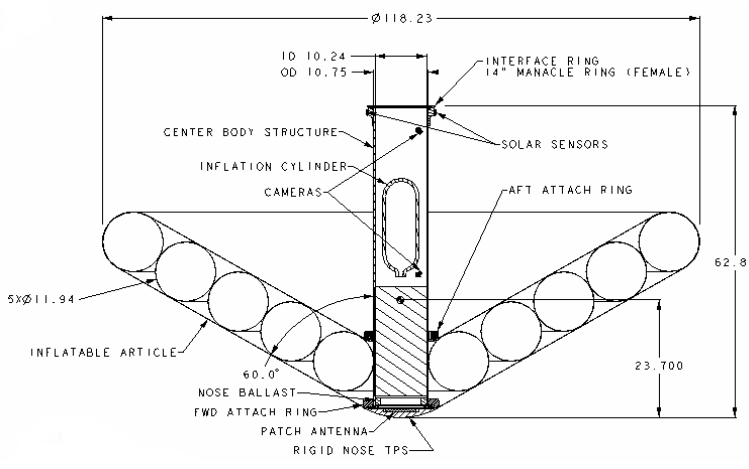

Figure 4. Initial IRVE system concept cross section (dimensions shown in inches). of the components based on function and capability. ${ }^{8-11}$ Material thicknesses and mass per unit area were multiplied by the calculated area to give initial estimates of aeroshell material volume and mass. A $25 \%$ margin was applied to both the volume and mass estimates to account for seaming and other unknowns. A conservative packaging efficiency of twice the margined material volume was used to calculate the stowage volume required to package the inflatable for launch. Assuming the inflatable was stowed in a uniform thickness annular volume around the vehicle structure the length of the payload shroud, the diameter of the payload shroud available for the IRVE structure and instrumentation was then determined. Subtracting the estimated inflatable aeroshell mass from the $100 \mathrm{~kg}$ launch vehicle performance limit set the mass allotted to the experiment structure and instrumentation. A conceptual design of the system was developed to fit within the allotted volume and within the mass constraints indicating the system was feasible for this small launch shroud.

Mass and inertia properties for the IRVE concept were provided to the WFF personnel so that they could model the IRVE trajectory through launch vehicle separation. LaRC personnel then used the WFF delivery states to develop the trajectory of IRVE from launch vehicle separation to water impact. Figure 5 shows the resulting concept of operations for the IRVE. The vehicle will be launched from Wallops Island. Shortly after second stage burnout, the payload consisting of the IRVE system, the launch vehicle telemetry module (T/M), and the nose cone will eject from the launch shroud as an assembly. After coasting to a safe separation from the second stage and launch shroud, the IRVE system will separate from the T/M-nosecone assembly. The restraint bag around the inflatable will be 
released and the aeroshell will be inflated prior to atmospheric interface. The IRVE system will decelerate from hypersonic through subsonic regime and impact the water at a terminal velocity of approximately $17 \mathrm{~m} / \mathrm{s}$. Temperature, pressure, video, translational accelerations, and orientation data will be transmitted to ground stations during all phases of flight, and the vehicle will also be tracked by radar.

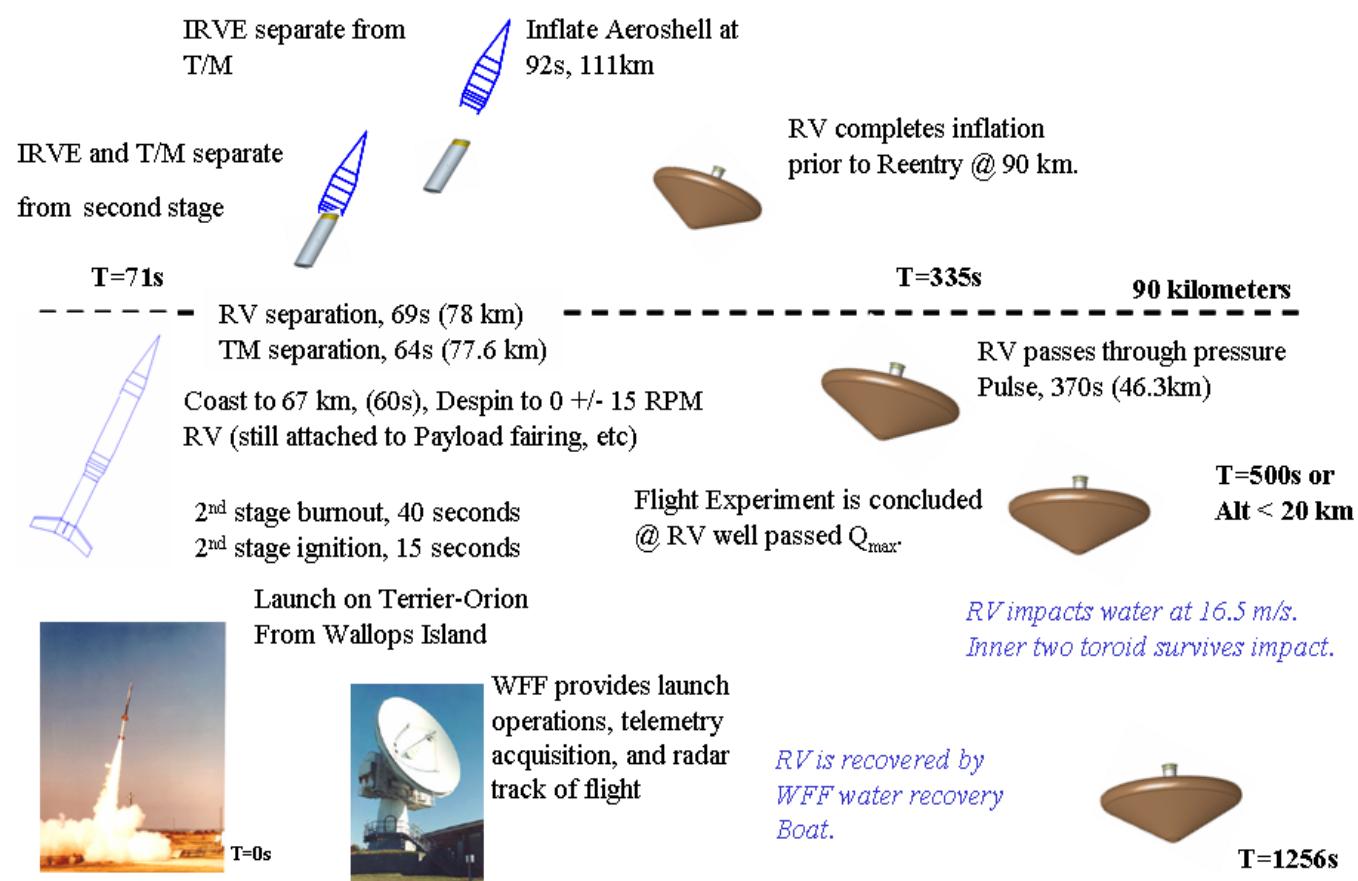

Figure 5. IRVE concept of operations.

\section{System Description}

The IRVE system is comprised of four major subsystems: a.) inflatable aeroshell, b.) centerbody structure, c.) electronics, and d.) inflation system.

\section{A. Inflatable Aeroshell}

The inflatable aeroshell subsystem is composed of four sub-elements: inflatable bladder, structural restraint, gas barrier, and thermal protection layer. Working with ILC Dover the inflatable design was refined as shown in Fig. 6.

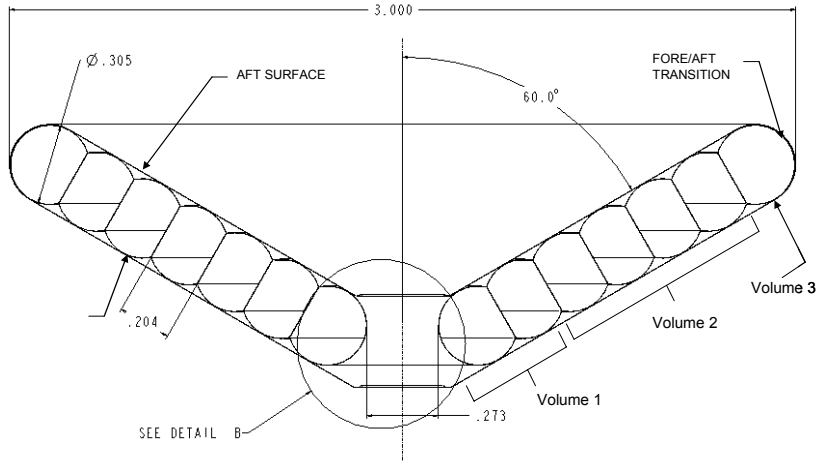

Figure 6. ILC inflatable structure concept (dimensions shown in meters).

The inflatable bladder is broken into three isolated volumes. The separate volumes add system robustness preventing a single puncture from causing catastrophic failure of the inflatable. The bladder material is a silicone coated Kevlar fabric recommended by ILC based on their experience with other rugged space inflatable systems. The coated fabric offers significantly greater tear resistance than a film bladder without a substantial weight penalty. The coated fabric bladder also has roughly the same temperature capability of the film bladder when film bonding temperature limits are considered. The three bladder volumes are laced together to create a single bladder element. A dry Kevlar fabric restraint layer holds the bladder assembly to the centerbody structure providing the load path for atmospheric entry and water impact loading. The restraint ply is captured in a "dead man" groove at the forward surface and laced to a mounting ring at the aft surface. The bladder is laced to the restraint at the maximum diameter and at the aft lacing ring. 
The restraint ply also serves as a mounting surface for the re-entry gas barrier and thermal protection layer. Both layers are stitched to the restraint layer. The gas barrier, composed of Kapton (polyimide film), prevents hot gasses from being drawn through or infiltrating the thermal protection layer preventing the restraint and bladder subelements from being directly exposed to the heat of re-entry. The thermal protection layer for IRVE is composed of layers of Nextel 312 cloth. Figure 7 shows the ply configuration of the inflatable aeroshell from the forward to the aft surfaces.

While more than adequate for the IRVE mission entry heating, the thermal protection layer will require a more capable lay-up for future higher heating missions. Investigations are underway into ceramic cloths, felts and battings that can be used to bolster the insulating capability behind the Nextel cloth.

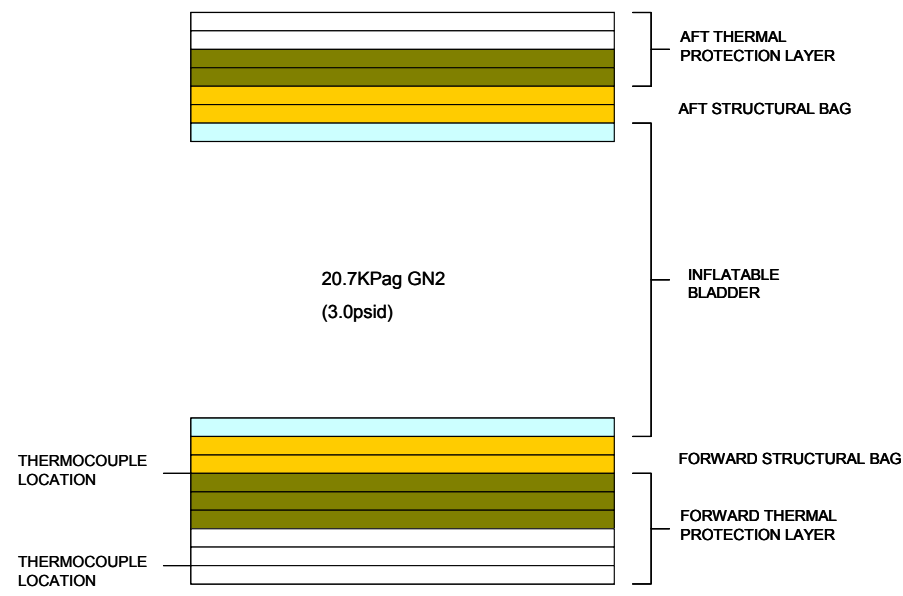

Figure 7. Inflatable ply configuration.

\section{B. Centerbody Structure}

The centerbody structure (shown in Fig. 8) is the backbone of the IRVE system. It provides the mounting structure for the inflatable aeroshell, the electronics and instrumentation package and the inflation system. It also provides the structural attachment to the launch vehicle. The primary component is a cylindrical aluminum shell.

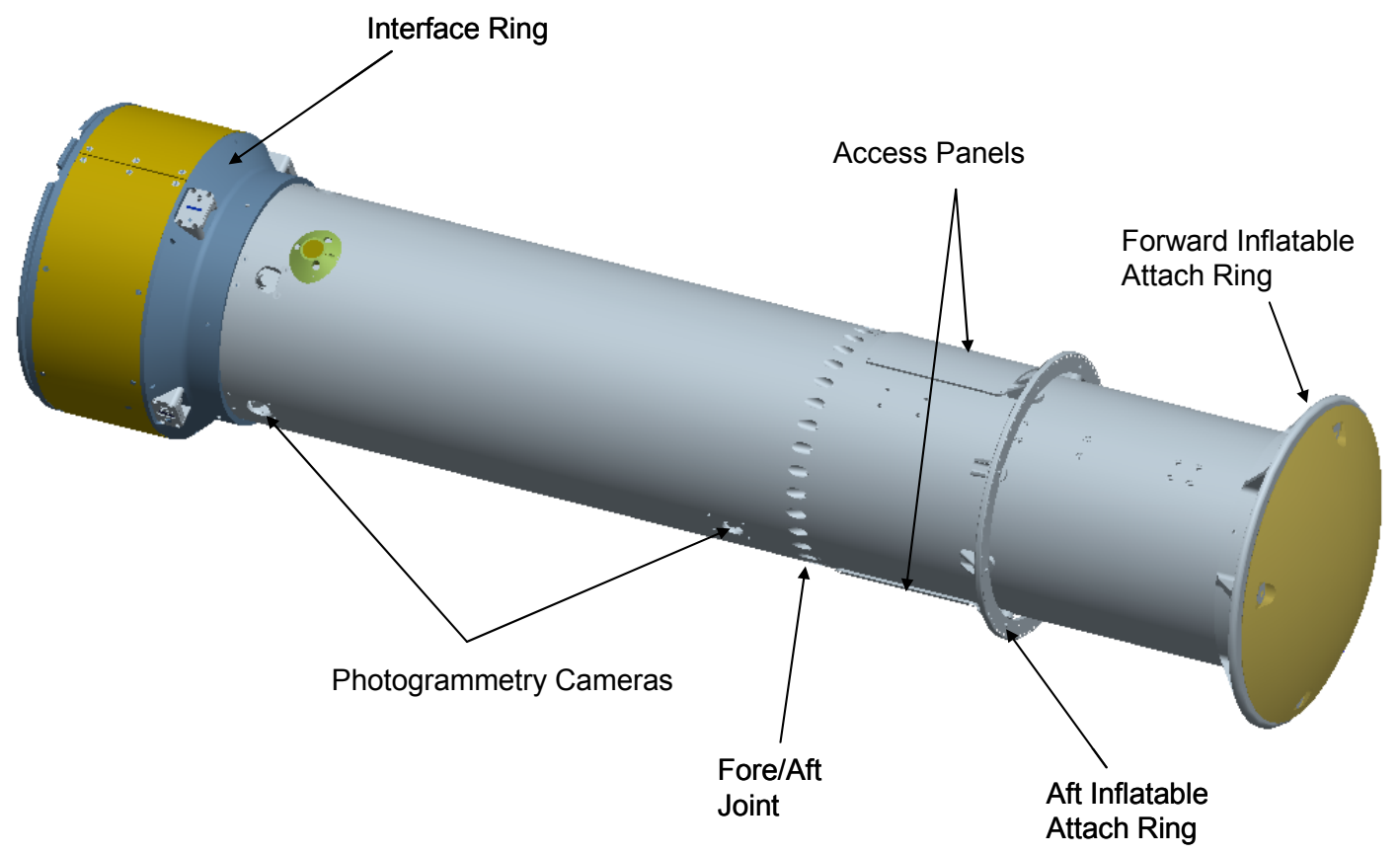

Figure 8. Centerbody structure with inflatable removed for clarity.

The shell is constructed in two pieces with a bolted joint in roughly the middle of the tube. The forward tube segment houses the electronics assembly while the aft segment houses the inflation system. The inflatable aeroshell 


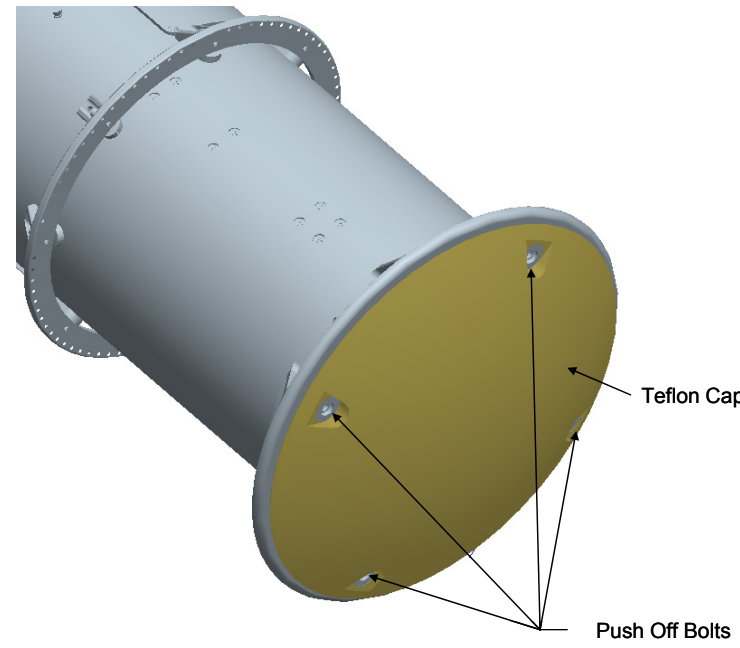

Figure 9. Spherical nose cap detail view.

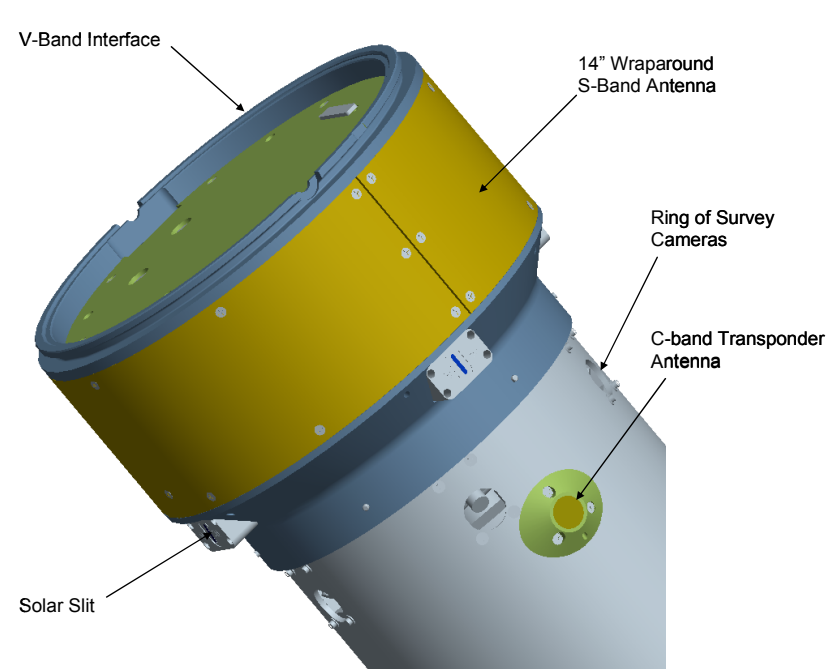

Figure 10. Interface ring detail view.

attached to the forward tube segment with front and rear ring assemblies that are bolted to the tube. The inflatable aeroshell is folded and packed around the centerbody structure for launch and held in place with a fabric bag. A capping assembly (see Fig.9) is bolted atop the forward attach ring assembly to provide a spherical nose to the vehicle. The spherical nose is an RF-transparent Teflon component protecting one of the two S-Band downlink antennas. The bolts retaining the Teflon nose also serve as the push points for the spring cartridges that eject the IRVE from the launch vehicle payload shroud. Two access panels in the aft end of the forward centerbody segment provide access to the electronics plate for integration and serve as exit ports for the fill lines running from the inflation system to the inflatable. Thermocouple leads for the aeroshell are also routed through the access panels. Photogrammetry and survey cameras are mounted to the aft centerbody segment, as well as antennas for the C-Band radar transponder. Figure 10 shows the launch vehicle interface ring mounted to the aft end of the aft segment. The interface ring contains the v-band interface which serves as the primary structural attachment to the launch vehicle. The interface ring also serves at the mounting surface for the 14" wrap around, S-Band primary downlink antenna.
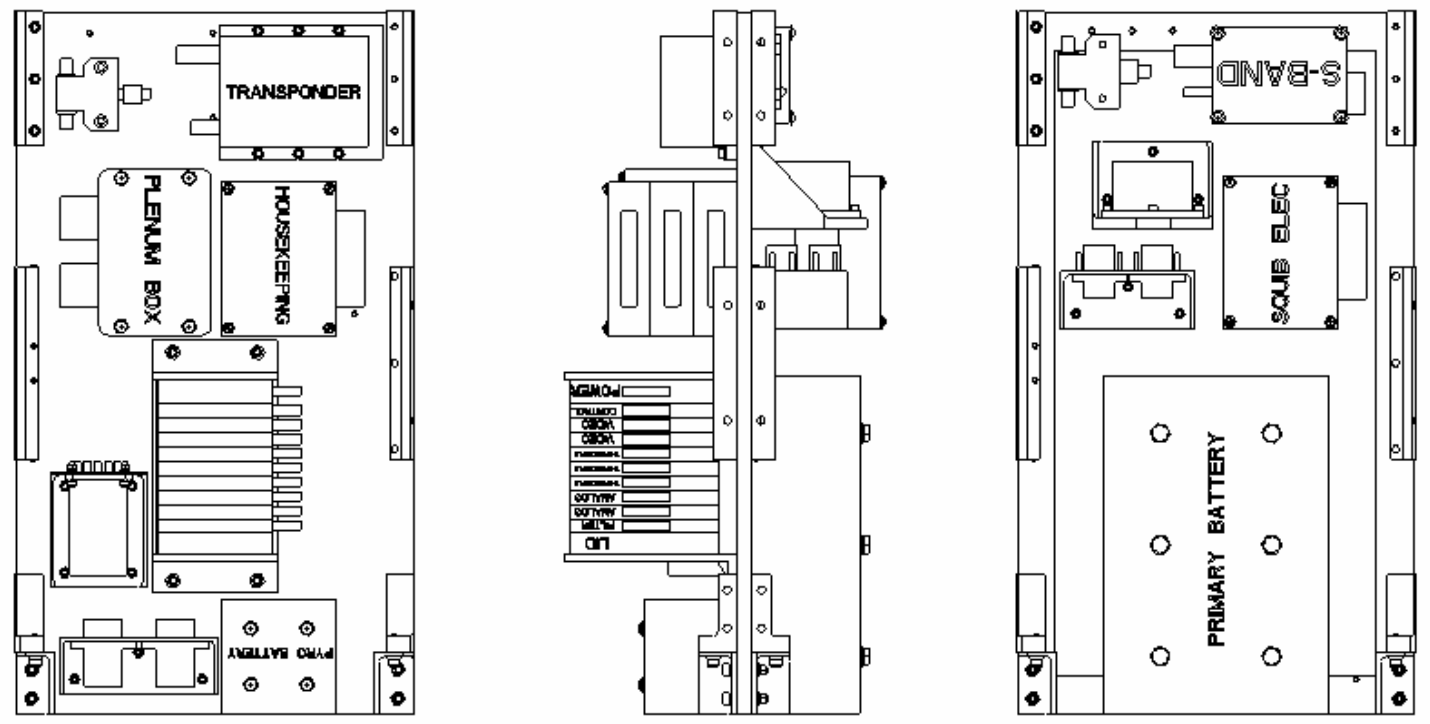

Figure 11. Electronics plate assembly

\section{Electronics}

Electronics were chosen from the NASA Sounding Rocket Program stores wherever possible to save cost and development schedule. Most of the electronic components are mounted to a single electronics plate to facilitate 
integration and checkout. The electronics plate (see Fig. 11) can be assembled wired and functionally checked prior to mounting it as a module inside the forward centerbody segment.

\section{Inflation System}

The inflatable aeroshell is pressurized shortly after separation from the launch vehicle through water impact with dry nitrogen blow down from a storage bottle. Flow from the bottle is initiated with redundant pyrotechnic valves. High pressure bottle gas is regulated down to bladder inflation pressure with a two stage regulator system set to maintain three psi over ambient. Inflation gas is manifolded into the three separate inflation volumes and each leg is protected with a check valve that prevents back flow of the gas out of that inflatable volume. This check valve prevents a rupture of one of the inflatable volumes from deflating the remaining two volumes. If one of the volumes is damaged during the separation process and is unable to maintain pressure each fill line to the separate volumes will have an orifice to restrict free flow through the line. The orifices will be sized to restrict the flow enough that there will be adequate gas in the fill bottle to maintain pressure in the remaining two volumes through the entry pressure pulse.

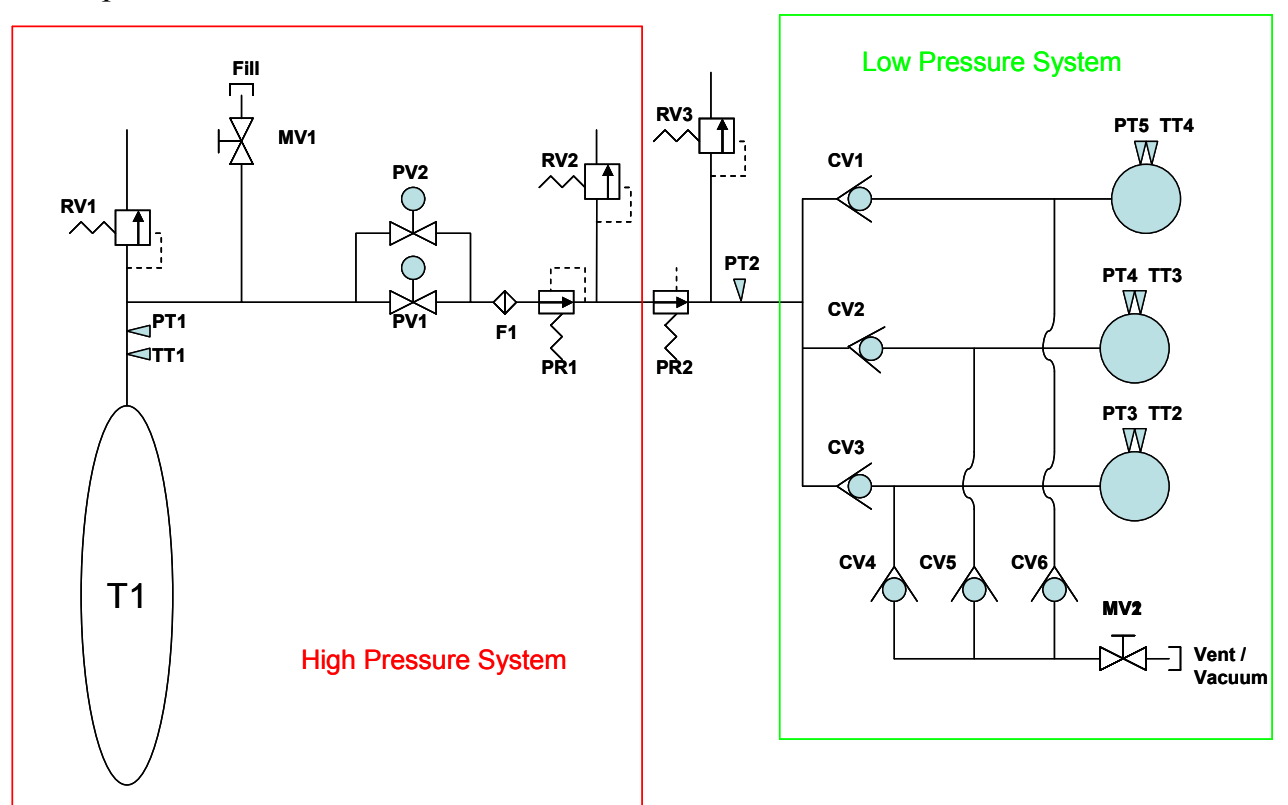

Figure 12. IRVE inflation system schematic.

An evacuation port is provided to evacuate the bladders for launch stowage of the aeroshell. A high pressure fill port is available for servicing the fill bottle. Relief valves prevent over pressurization of any portion of the system. Each bladder volume pressure is monitored with a transducer. Transducers also monitor bottle pressure and manifold pressure down stream of the of the regulator pair. Fill bottle temperature is monitored with a thermistor. All measurements are included in the downlink data stream for verification of system flight performance. The inflation system schematic is shown in Fig. 12.

\section{IRVE Analyses}

Several analyses were required to develop the design requirements. A trajectory simulation was required to determine stagnation pressure, stagnation point heating and deceleration imparted to the IRVE system. The trajectory also produces an event timeline that is needed to size the inflation gas system. Computational Fluid Dynamics (CFD) was used to determine the pressure and heating distributions over the entire aeroshell surface at key points along the trajectory. Structural analysis was performed to determine appropriate retention bag and bladder materials and layups. Structural analysis was also employed to size the centerbody components to survive launch and impact loads. Thermal analysis was performed to verify the selection of thermal protection materials was sufficient to protect the restraint plies and bladders from the heat pulse. Thermal analysis of the centerbody components in particular the electronics plate has been performed to determine allowable operation schedules for the instrumentation. 


\section{A. Trajectory Analysis}

A high fidelity, 6-DoF (degree of freedom) simulation of IRVE's trajectory from booster separation to splash down was used to determine dynamic pressure, deceleration and heating environments along with IRVE's longitudinal stability during reentry. The simulation was created and executed using the Program to Optimize Simulated Trajectories (POST) ${ }^{12}$ using boost states, aerodynamics, mass properties and atmosphere models specific to IRVE. Elapsed time, position, velocity, attitude and attitude rates at booster separation were obtained from the WFF boost trajectory simulation and used to initialize the POST simulation. The aerodynamics model was based on the Genesis high-fidelity aerodynamic database. ${ }^{13-14}$ It was modified by incorporating aero coefficients (both static
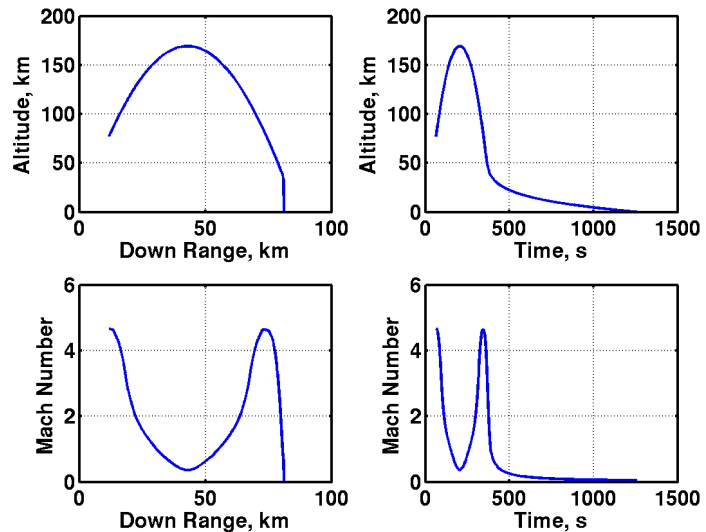

Figure 13. IRVE altitude and Mach number vs. downrange and time.
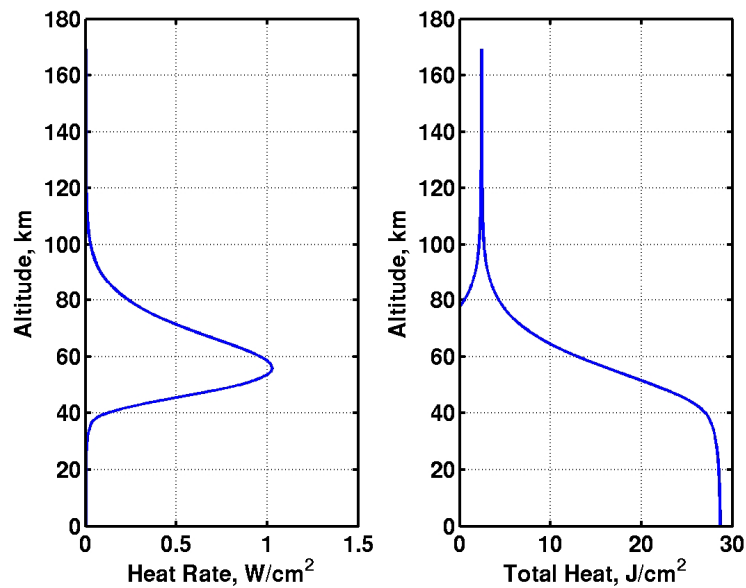

Figure 15. IRVE heat rate and total heat load vs. altitude.
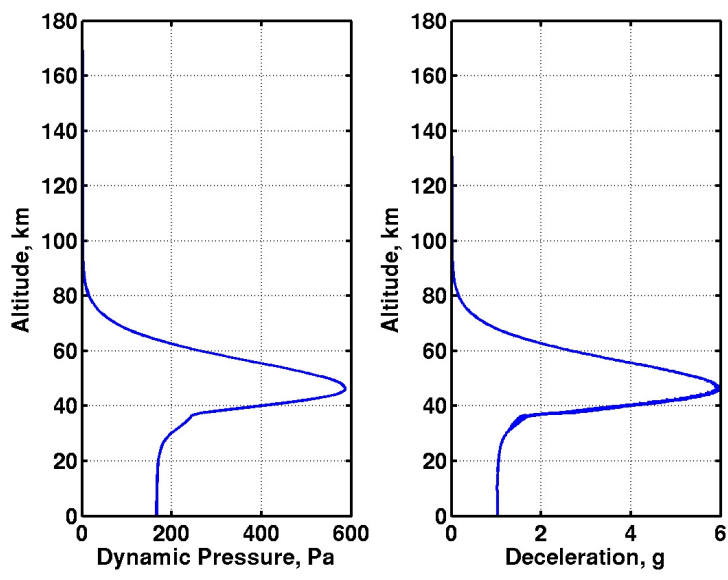

Figure 14. IRVE dynamic deceleration vs. altitude. pressure and
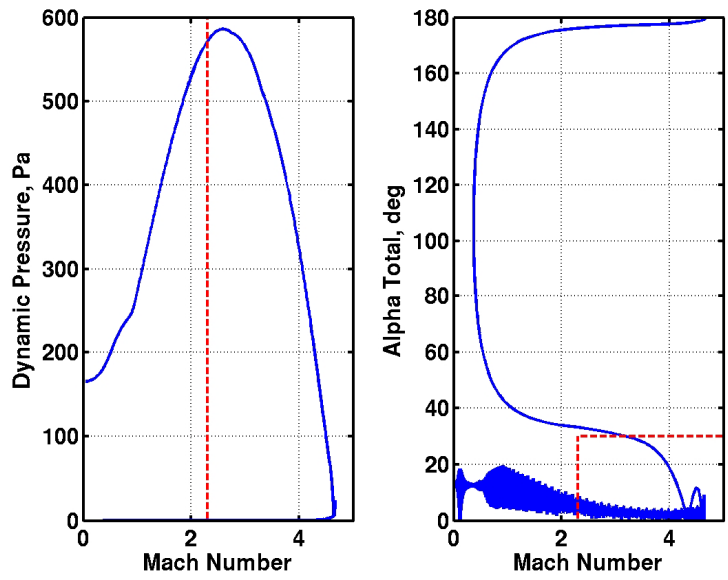

Figure 16. Dynamic pressure and total angle of attack vs. Mach number.

force coefficients and attitude rate derivatives) from existing ballistic range data for 60-deg sphere-cone aeroshells with afterbodies more similar to IRVE. Mass, inertia and center of gravity (CG) (as a function of aeroshell deployment geometry) were obtained from the IRVE ProEngineer ${ }^{15}$ CAD model and incorporated into the simulation. The Sutton-Graves stagnation point convective heat rate relationship ${ }^{16}$ with IRVE's $0.38 \mathrm{~m}$ nose radius was used in the simulation as a heating indicator.

Figure 13 shows IRVE's altitude and Mach number as a function of down range position and time. IRVE reaches a peak altitude of $169 \mathrm{~km}$, a peak reentry Mach number of 4.64 and travels $81 \mathrm{~km}$ downrange 1192 seconds after separation. The exo-atmospheric flight time is approximately 240 seconds while the time from reentry to splash down is approximately 920 seconds. Figure 14 shows deceleration and dynamic pressure as a function of altitude. IRVE experiences peak reentry dynamic pressure and deceleration of approximately $600 \mathrm{~Pa}$ and $6 \mathrm{~g}$ 's respectively at 
$47 \mathrm{~km}$ (306 seconds after separation). Figure 15 shows the Sutton-Graves heating indicator as a function of altitude. Peak heating of approximately $1 \mathrm{~W} / \mathrm{cm}^{2}$ occurs at $56 \mathrm{~km}$ (297 seconds after separation). To keep the stagnation point on the nose of the vehicle IRVE's total angle of attack (AOA) must not exceed 30 deg at reentry and must remain below 30 deg until after peak dynamic pressure has been reached. Figure 16 shows total AOA and dynamic pressure as a function of Mach number. IRVE's total AOA is 180 deg at separation. As the flight path angle decreases the AOA decreases. Upon reentry at Mach 4.6, aerodynamic forces align IRVE to the flight path but induce attitude oscillations. The aerodynamic attitude derivatives damp the oscillation and limit the AOA oscillations to 10 deg through Mach 2.0 (well past the peak dynamic pressure at approximately Mach 2.5).

\section{B. CFD}

The Langley Aerothermodynamics Upwind Relaxation Algorithm (LAURA) $)^{17,18}$ CFD code was used to determine the predicted surface heating distribution along the trajectory. Freestream conditions at the trajectory's peak stagnation heating point were extracted from the POST simulation results. These conditions were used as inputs for axisymmetric CFD solutions that provided radial heating distribution. The normalized surface heating distribution shown in Fig. 17, coupled with the stagnation heating pulse along the trajectory, was used in a thermal model of the inflatable aeroshell to predict component temperatures in the inflatable aeroshell throughout the entry. Similarly, the radial surface pressure distribution, obtained using CFD at peak stagnation pressure conditions extracted from the trajectory, was used in a structural model of the inflatable aeroshell to predict fabric loading in the inflatable, and fundamental frequencies of the loaded inflatable.

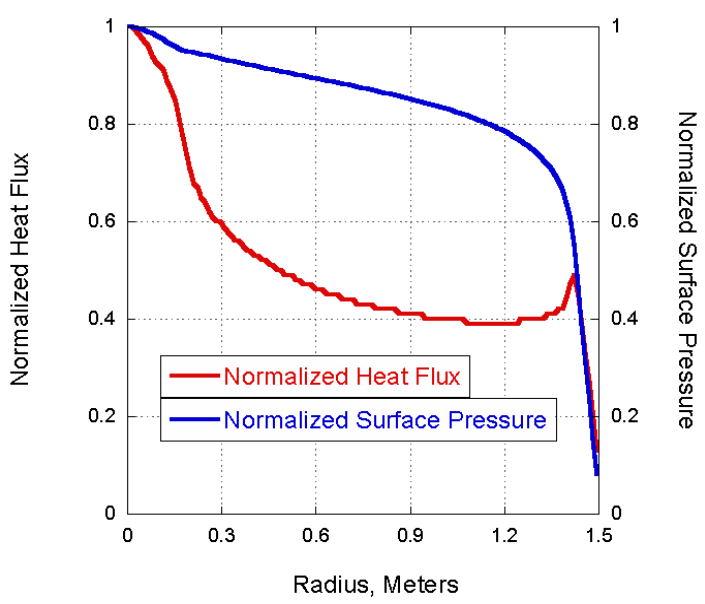

Figure 17. Normalized radial heat flux and surface pressure distribution on a preliminary IRVE concept from LAURA

\section{Structural Analyses}

A structural analysis was performed on the inflatable structure using MSC.Marc $\AA .{ }^{19}$ The model first computed fabric loading due to the internal inflation pressure then solved for the dynamic pressure load on the results of the internally pressurized solution. Figure 18 shows the simplified 15-deg wedge model which takes advantage of the vehicle symmetry. Solving for the fundamental frequencies of the pressurized inflatable required the modeling of the entire 360-deg body of revolution. Figure 19 shows the results of the first mode of the pressurized loaded inflatable.

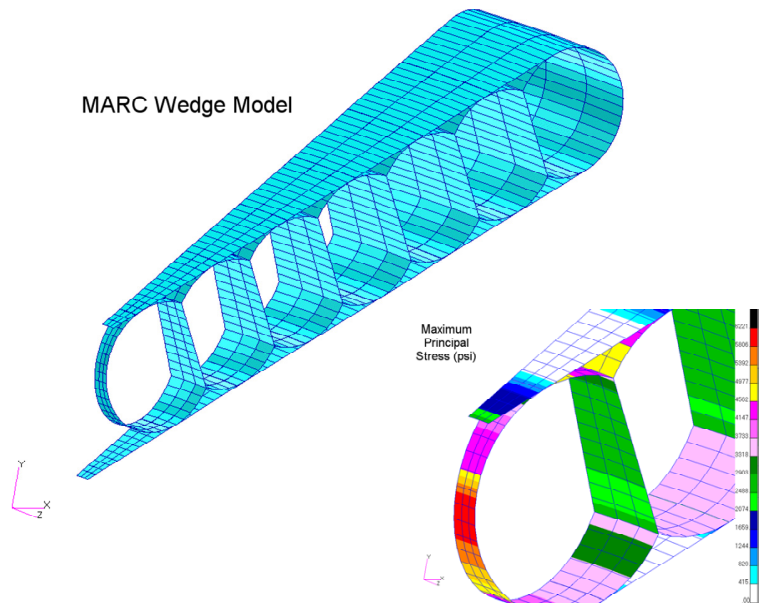

Figure 18. MARC wedge model, 5 psi internal pressure 6ksi max skin stress.

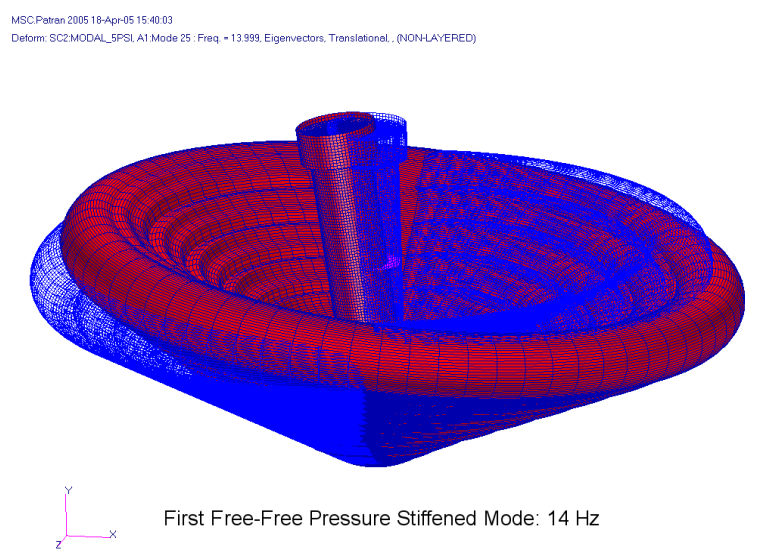

Figure 19. First mode of the inflated aeroshell, $14 \mathrm{~Hz}$. 
Structural modeling of the centerbody is required to verify the system will withstand launch loads. In addition due to the IRVE being mounted to the launch vehicle in a non-standard configuration, initial analysis was required to determine the design input loads required for IRVE. Figure 20 shows the model used to determine the IRVE input loads. Design loads from the SRPH were applied to the interface between the second stage and payload shroud (base of the model shown in Fig. 20) to produce interface loads to the IRVE attachment on the vehicle T/M.

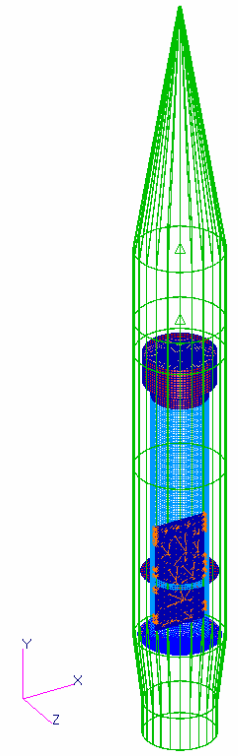

Figure 20. Structural model to determine interface loading

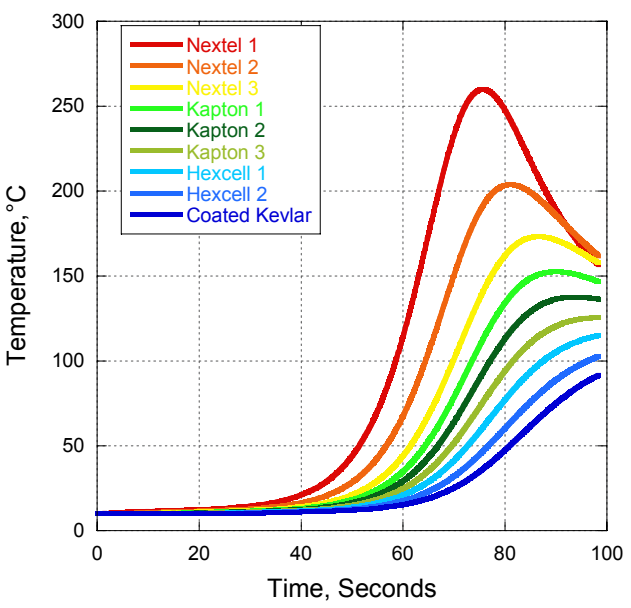

Figure 21. 1-D Thermal analysis results for ply temperatures.

\section{Thermal Analyses}

1-D transient thermal models were used as a first cut to verify the fabrics used in the inflatable construction were configured in a manner that would survive the IRVE entry. For conservatism the stagnation heating was used in the 1-D models. Figure 21 shows the resulting ply temperatures. In the future a 3-D thermal model will be constructed and the radial heating distribution applied to the surface. A 3-D MSC P-Thermal ${ }^{20}$ model was created for the centerbody structure and the electronic components. The model is used to predict allowable operating times for the electronic components. Figure 22 shows a contour plot of the electronics plate after 23 minutes of operation (the time from launch to water impact) with the primary thermal contributors (the S-Band Transmitter, the C-Band Transponder, and the PCM stack) visible. Figure 23 shows a time history of critical component temperatures.

MSC.Patran 2005 27-Apr-05 14:37:40

Fringe: TIME: $1.8000000000 \mathrm{D}+03$ SECONDS, nr030.nrf01, Tempe

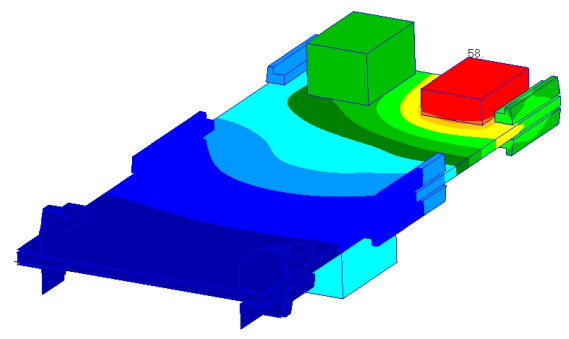

$$
\mathrm{X}_{\mathrm{Y}}
$$

Z

Figure 22. Temperature contour plots at end of mission of initial electronics plate layout.

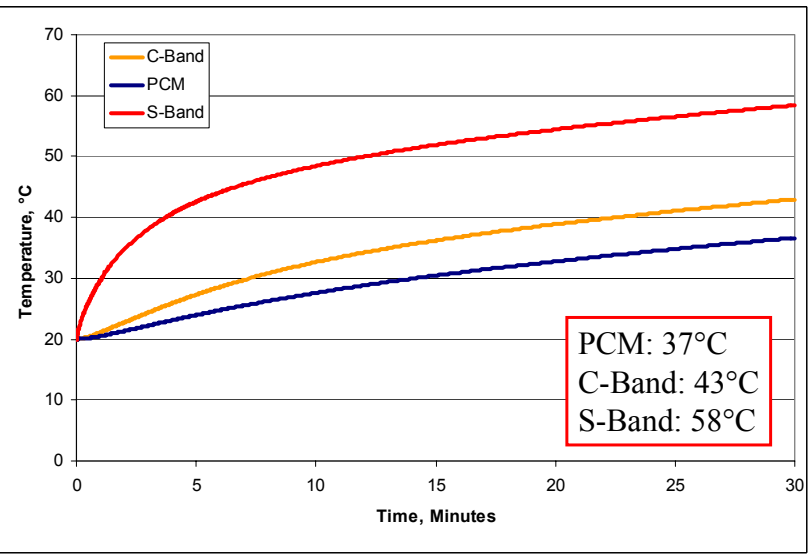

Figure 23. Critical component temperature traces. 


\section{Instrumentation}

Several data products will be collected during the IRVE flight to measure the performance of the system. Acceleration and orientation of the vehicle will be measure with a NASA Sounding Rocket Operations Contract (NSROC) device called the Sub-A. The Sub-A has an integral three-axis accelerometer, a ring accelerometer, a magnetometer, and four external slit sensors equally spaced about the body. The accelerometers provide acceleration data that is integrated to produce velocity and position. The ring accelerometer is four accelerometers placed in a ring inside the Sub-A housing. The housing is mounted in the vehicle such that the ring accelerometer axis is aligned with the spin axis of the vehicle allowing the vehicle roll rate to be measured. Vehicle attitude, required to make use of the three-axis accelerometer data, is determined with the magnetometer and solar vector solution from the slit sensors. A radar transponder is used in conjunction with several ground tracking stations to produce a radar track that will be used as a cross check of Sub-A trajectory reconstruction.

On-board video cameras shown in Figs. 8 and 10 will not only provide video documentation of the flight, but are also configured to produce photogrammetric solutions of the motion of the inflatable aeroshell. After inflation a video switch will index through five cameras equally spaced around the aft end of the centerbody to provide a photo survey verifying the vehicle achieved the proper shape at inflation. The last photo survey camera is aligned with another video camera positioned about 28 inches farther forward in the centerbody. This forward camera remains on and un-switched throughout the flight and should guarantee a video record of a 72-deg wedge of the inflatable in the event of a failure of the switched camera set. If there is no failure in the switched camera set the two cameras will have overlapping views of a 72-deg wedge of the aeroshell that will be populated with high contrast targets. Knowing the relative positions of the cameras allows the determination of the deflection of the targets perpendicular to as well as in the plane of the target surface. The shape history of the target surface will be reconstructed from the deflection time history of the target set.

Twenty-four thermocouples will be embedded in the inflatable to provide skin surface and in-depth temperature measurements. Figure 24 maps the location of the thermocouples. There will be three primary radials 120 deg apart.

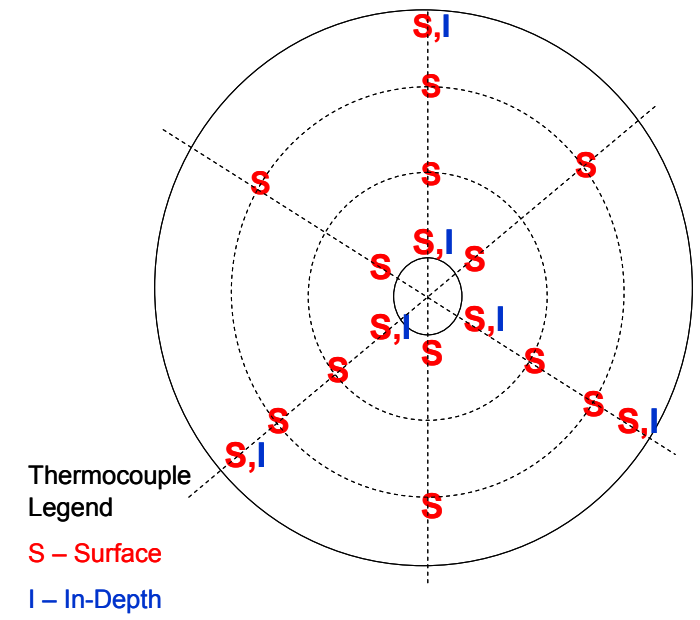

Figure 24. IRVE thermocouple map. On each radial there will be four surface temperature thermocouples, at $0.2 \mathrm{~m}, 0.62 \mathrm{~m}, 1.04 \mathrm{~m}$, and $1.45 \mathrm{~m}$ radius from the vehicle centerline. In-depth thermocouples will be located under the inner and outer surface thermocouples. The surface temperature thermocouples will be directly under the outer Nextel ply of the TPS layer. This measurement will validate aerothermal modeling heating predictions. In-depth thermocouples will be placed between the final Kapton ply of the TPS layer and the outer Kevlar ply of the restraint layer. This measurement will verify the performance of the TPS layer and validate the thermal modeling of the inflatable system. The outer in-depth measurement will also indicate whether hot gases are flowing into the fabric in the higher shear flow of the shoulder region. Between the primary radials are three additional radials with only two surface temperature thermocouples each, one at $0.2 \mathrm{~m}$ and one at $1.04 \mathrm{~m}$ radius from the vehicle centerline.

Pressure transducers will be used to monitor the internal pressure of each of the three separate inflatable volumes which will indicate if the inflatable is punctured. A transducer will also be employed to monitor the inflation gas bottle pressure. This measure will verify there is enough inflation gas in the blowdown tank to complete the mission and will be used as one of the launch criteria. Inflation tank pressure drop above the predicted rate will indicate a system leak and be used as a cross check for other leak indicators. A pressure transducer downstream of the differential regulator set and another transducer measuring ambient pressure inside the centerbody will be used to verify regulator performance and will also confirm that the pyrovalves successfully opened.

\section{Work to Date}

Ballistic range testing was performed for the IRVE configuration at the end of calendar year 2004. The tests were conducted at the Aeroballistic Research Facility (ARF) which is located at Eglin Air Force Base in Florida. In 


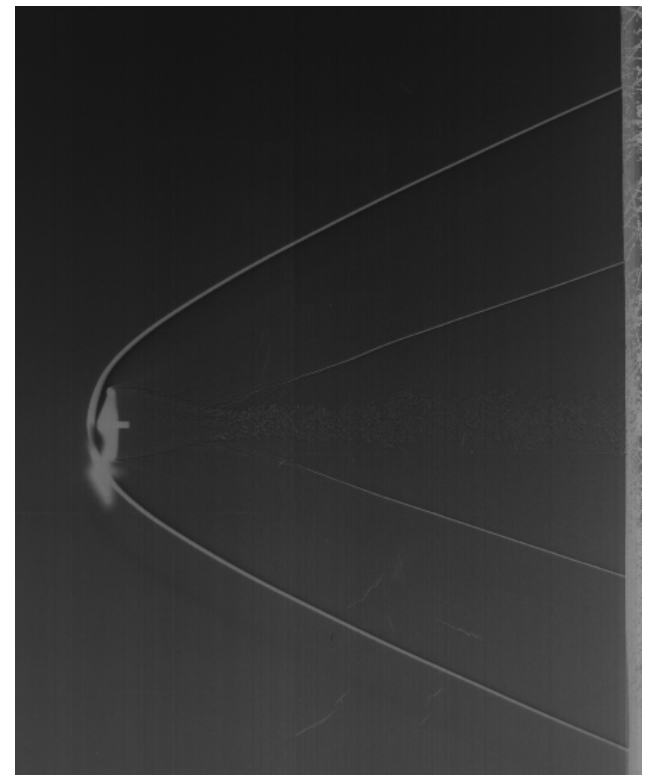

Figure 25. Ballistic range station shadowgraph

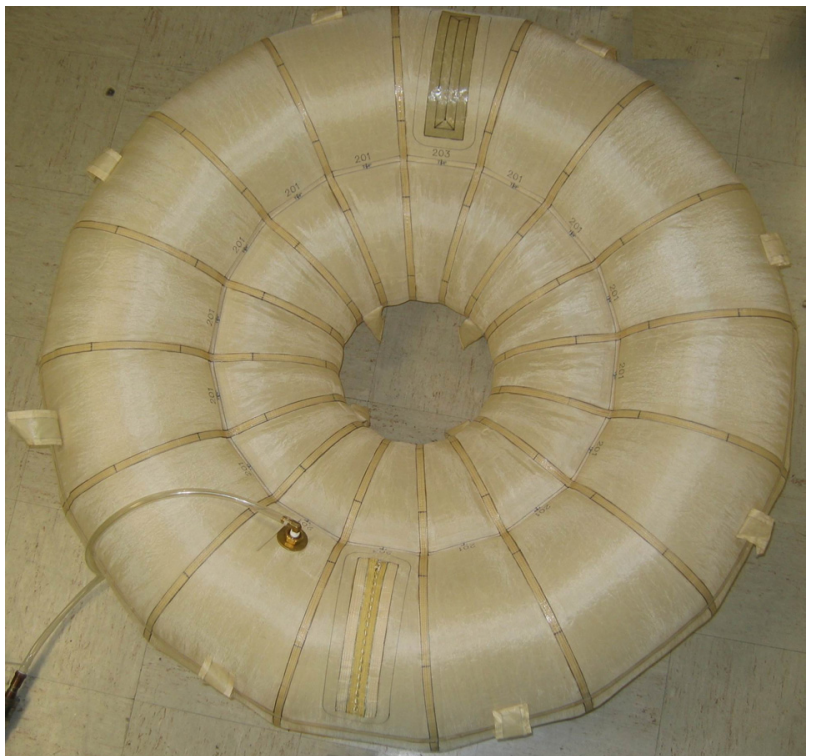

Figure 26. Bladder of the PVU.

ballistic range testing a model is packaged in a sabot and fired down an instrumented test range. At various stations down the range shadowgraphs are taken in two planes perpendicular to the line of travel. The shadowgraphs are very accurately time stamped to develop a time history of position and orientation of the model. Using the position and orientation data a flight trajectory of the model is reconstructed. Knowing the atmospheric properties and the flight trajectories allows the calculation of vehicle aerodynamics. ${ }^{21}$ The calculated aerodynamics of the vehicle are then tabulated in a database for use within POST trajectory predictions. Figure 25 shows a shadowgraph of the IRVE model during a ballistic range shot. Data from the range indicates that the IRVE shape is both statically and dynamically stable from hypersonic through subsonic flight.

ILC Dover has constructed both a Pattern Validation Unit (PVU) and a Design Validation Test (DVT) unit of the first bladder volume of the inflatable. The PVU was constructed out of materials the inflatable manufacturer had in stock that were similar (as far as construction is concerned) to the flight materials. This unit allowed the manufacturer to refine construction techniques for the IRVE inflatable configuration without sacrificing expensive long-lead-time flight materials. Figure 26 shows the bladder portion of the PVU. Once the shape produced by the PVU was deemed acceptable, the DVT (another prototype of the first IRVE bladder volume) was constructed from the proposed flight materials. Shortcomings in the initial design concept were discovered with the DVT and the unit was modified to eliminate the problems. The DVT changes have been incorporated into the design of the flight unit.

The DVT was delivered to LaRC in March 2005 for some additional testing. Unfortunately, some of the modifications to the DVT prevented using the unit for vacuum leak testing, but other tests were still possible. The DVT was inflated in an RF lab and the inflated structure was tested to verify that it would not interfere with transmission of telemetered data during the flight. Structural transient response testing was also performed on the DVT to help refine the structural models of the IRVE.

\section{Future Work}

The Critical Design Review of the IRVE system is scheduled for June 2005. Following acceptance of the design by the review committee, we will begin to procure components and assemble the vehicle. Delivery of the IRVE system to WFF is scheduled in September 2005 for integration to the launch payload assembly. After integration into the payload fairing environmental testing will be conducted culminating in an end-to-end functional test which includes all pyro events. The payload will then be integrated with the launch vehicle and launched in November of 2005. Data analysis including trajectory reconstruction will be completed by the end of calendar year 2005 . 


\section{Acknowledgments}

Stephen J. Hughes would like to acknowledge the efforts of the entire IRVE team at NASA Langley, NASA Wallops, and ILC Dover. Without the efforts of this team this experiment (with an extremely compressed schedule) would not be possible. In addition to the authors listed direct contributions to this paper come from Dr. Brian R. Hollis (LaRC), Neal Hass (LaRC), Jim Corliss (LaRC), Jim Stein (ILC), Jody Ware, ILC, Megan Dixon (ILC), Brian Creighton (NSROC), and David Kilcoyne (NSROC).

\section{References}

${ }^{1}$ Cruz, J. R., Cianciolo, A. D., Powell, R. D., Simonsen, L. C., and Tolson, R. H., "Entry, Descent, and Landing Technology Concept Trade Study for Increasing Payload Mass to the Surface of Mars," 4th International Symposium on Atmospheric Reentry Vehicles \& Systems, March 21-23, 2005, Arcachon, France.

${ }^{2}$ Johnson, C., Tran, H., "Stardust Backshell and Back Interface Plate Design Verification Tests in the NASA Ames Arc Jet Facilities," AIAA Paper 97-2483, 32 ${ }^{\text {nd }}$ Thermophysics Conference, Atlanta, GA, June 23-25, 1997.

${ }^{3}$ MSL Project, "Mars Smart Lander Design Cycle 2 Review," Arcadia, CA, June 13 -14, 2002

${ }^{4}$ Mitcheltree, R. A. and Gnoffo, P. A.: "Wake Flow About a MESUR Mars Entry Vehicle," Journal of Spacecraft and Rockets, Vol. 32., No. 5, September-October 1995, pp. 771-776.

${ }^{5}$ Smith, D. E., Zuber, M. T., Frey H. V., Garvin. J. B., Head, J. W., Muhleman, D. O., Pettengill, G. H., Phillips, R. J., Solomon, S. C., Zwally, H. J., Banerdt, W. B., Duxbury, T. C., Golombek, M. P., Lemoine, F. G., Neumann, G. A., Rowlands, D. D., Aharonson, O., Ford, P. G., Ivanov, A. B., Johnson, C. L., McGovern, P. J., Abshire, J. B., Afzal, R. S., and Sun, X., 2001, "Mars Orbiter Laser Altimeter (MOLA): Experiment summary after the first year of global mapping of Mars," Journal of Geophysical Research, Vol 106, p. 23,689-23,722.

${ }^{6}$ Sounding Rocket Program Office, "Sounding Rocket Program Handbook," 810-HB-SRP, July 2001.

${ }^{7}$ C. J. Player, F.M. Cheatwood, J.M. Corliss, "Development of Inflatable Entry Systems Technologies," 3rd International Planetary Probe Workshop, June 27 - July 1, 2005, Athens, Greece.

${ }^{8}$ Kevlar Technical Guide, DuPont Advanced Fiber Systems, Richmond, VA.

${ }^{9}$ Nextel Ceramic Textiles Technical Notebook, 3M Ceramic Textiles and Composites, St. Paul, MN.

${ }^{10}$ Sheldahl Technical Materials, "Aerospace Thermal Control Materials and Films," Product Bulletins, November 9, 2001.

${ }^{11}$ Hexcel Schwebel, "Markets, Application, and Products," http://www.hexcelschwebel.com/Markets/default.htm [cited 29 April 2005]

${ }^{12}$ POST II, Trajectory Simulation Software, Ver. 1.16G, NASA LaRC.

${ }^{13}$ Desai, P. N. and Cheatwood, F. M., "Entry Dispersion Analysis for the Genesis Sample Return Capsule," Journal of Spacecraft \& Rockets, Vol. 38, No. 3, May-June, 2001, pp. 345-350.

${ }^{14}$ Cheatwood, F. McNeil; Winchenbach, Gerald L.; Hathaway, Wayne; and Chapman, Gary, "Dynamic Stability Testing of the Genesis Sample Return Capsule," AIAA Paper 2000-1009, 38th AIAA Aerospace Sciences Meeting \& Exhibit, Reno, Nevada, January 10-13, 2000.

${ }^{15}$ ProEngineer, Solid Modeling Design Software Package, Wildfire 2.0, Parametric Technology Corporation, Needham, MA, 2004.

${ }^{16}$ Sutton, K. S., and Graves, Jr., R. A., "A General Stagnation-Point Convective-Heating Equation for Arbitrary Gas Mixtures,” NASA TR R-376, November 1971.

${ }^{17}$ LAURA, Computational Fluid Dynamics Software, Ver 4.9.4, NASA LaRC, Hampton, VA.

${ }^{18}$ Cheatwood, F. McNeil; and Gnoffo, Peter A., "User's Manual for the Langley Aerothermodynamic Upwind Relaxation Algorithm (LAURA)," NASA Technical Memorandum 4674, April 1996.

${ }^{19}$ MSC MARC, Non-Linear Finite Element Analysis Software, Ver 2005, MSC Software Corporation, Santa Ana, CA, 2005.

${ }^{20}$ MSC P-Thermal, Thermal Analysis Software, Ver. 2004-R2, MSC Software Corporation, Santa Ana, CA, 2004.

${ }^{21}$ Chapman G. T., and Kirk, D. B, "A Method for Extracting Aerodynamic Coefficients from Free-Flight Data," AIAA Journal Vol. 8, No. 4, 1970, pp 753-757. 